\title{
When "The Program is Good, But the Disease is Better": Lessons from Peru on Drug-Resistant Tuberculosis
}

\author{
Sandy Smith-Nonini
}

This is a qualitative study of the politics of public health surrounding a resurgent tuberculosis epidemic in Lima, Peru during the 1990s. The paper traces the role of debt and neoliberal economics in creating conditions for the epidemic, and the reforms that turned Peru's TB program into a model for treating drug-susceptible disease by 1996. Despite this success, public health officials were blind-sided by the appearance of drug-resistant TB in the late 1990s when their "good" program turned out to be not good enough. The study follows the conflict, and eventual collaboration, that ensued between the Ministry of Health and a local NGO affiliated with Boston-based Partners in Health, which undertook a radical program of community-based directly-observed therapy (DOTS-Plus) to treat drug-resistant patients who otherwise would have died. Lessons from this case are relevant to many international settings where "hot-spots" of drug-resistant TB currently exist and go untreated, posing a threat to the success of national TB control programs.

Key Words: infectious disease; drug-resistant tuberculosis; international health

The focus of media and public health attention on the tragic death toll from acquired immune deficiency syndrome (AIDS) in Africa has to some degree overshadowed another public health menace-that of resurgent tuberculosis (TB). In fact, tuberculosis infections are often the actual cause of death of many AIDS patients. Despite the availability of effective drugs, TB epidemics today kill three million people annually and, according to the

SANDY SMith-Nonini, Ph.D., is an assistant professor in the Department of Sociology and Anthropology at Elon University. She may be reached at 2030 Englewood Avenue, Durham, North Carolina, 27705, USA; Phone: (919) 286-7396; E-mail: snonini@elon.edu 
World Health Organization (WHO), constitute the largest preventable cause of adult disability and death in the world. The persistence of tuberculosis is tied to the social context of its spread as well as to the difficulty of its cure. In the 1990s it became clear that drug-resistant tuberculosis strains had caused quiet epidemics among the poor in numerous countries, particularly in settings where AIDS, warfare, or worsening poverty had reduced immunity (Cohn 1997; Farmer 1997; Pablos-Mendez et al. 1998). The high cost of treating multiple-drug-resistant tuberculosis (MDRTB) fostered a tendency among public health authorities to ignore the problem. But the high fatality rate and potential for airborne spread of the bacillus by drug-resistant patients, many of whom remain mobile and active, means that we will face a larger health crisis down the road if health authorities do not find a comprehensive strategy for curing MDRTB-infected populations.

This article is a qualitative study of the cultural politics of resurgent TB in Lima, Peru, one of the "hot spots" of international MDRTB. It is intended to highlight the ways in which political and economic interests, both locally and internationally, shaped the response of local governments to the re-emergence of TB in the 1990s, contributing to delays in the funding of necessary treatment and prevention programs. My findings are based in part on 45 open-ended, in-depth interviews with patients, health workers, academics, and current and former public health officials involved with TB control. I conducted interviews and observed TB treatment programs and facilities during a six-week visit to Lima in 1999. Outside of Peru I conducted interviews with public health workers and officials who had gained experience with resurgent TB in Atlanta, New York City, Geneva, and Boston. I also reviewed conference proceedings and the emerging literature on drug-resistant $\mathrm{TB} .{ }^{1}$

From the standpoint of medical anthropology, TB is of particular interest because of the challenge it poses to health care systems. On the one hand, successful control of TB requires health workers to transcend the dominant curative care paradigm of Western biomedicine: there is no "magic bullet" that will cure TB. Once patients are infected, drug therapy must continue for six to twelve months, long after patients begin to feel better. Since incomplete treatment leads to drug-resistant strains of the bacillus, doctors have long regarded patient compliance as one of their biggest challenges.

According to WHO, the best model for TB control in epidemic situations is directly observed therapy (DOT), which involves 
health aides actually observing patients take their pills. Clearly, this is an approach that calls for an unusually high level of collaboration between physicians, patients, and health workers. Most DOT programs were administered in Third World settings until the late 1980s, when epidemics of drug-resistant TB began to appear in pockets of impoverished inner cities in Europe and the United States, including London, New York City, Atlanta, Fort Worth, San Francisco, and Baltimore. An adaptation of DOT was credited with helping to bring epidemics of drug-resistant strains under control in several of these urban settings (Weis et al. 1994; Chaulk et al. 1995; Frieden et al. 1995). But DOT was controversial in the United States as it involved public health protocols that overrode the traditional doctor-patient relationship so highly valued in the West. Furthermore, in the aftermath of public attention to the rights of HIV-positive patients, the rigidity of DOT protocols drew criticism from patient advocates, leading to debates about its acceptability (Bayer 1998; Heymann et al. 1998).

Interestingly, the spread of MDRTB is demonstrating the shortcomings of international public health models, which tend to over-rely on standardized treatment protocols administered through hierarchical bureaucracies. Programs that pay insufficient attention to cultural difference and diversity of needs at the community level, and that fail to adequately individualize treatments or to provide continuity of care, are also likely to fail to check the spread of drug-resistance, as the Peru case demonstrates.

Peru's public health system is resource-poor and shaped by international health development models. After a decade of economic turmoil and war, by the end of the 1980s tuberculosis control (as well as other health programs) had failed, leaving the country with the highest prevalence of TB in Latin America (Cueto 1997). While nearly three-quarters of the population in this largely rural country rely on the public system, Peru's health ministry, not unlike other Latin American government health ministries, has remained highly centralized and politicized, with a tradition of being led by urban physicians. In the aftermath of the famous cholera epidemic in 1992, the current president, Alberto Fujimori, belatedly acknowledged Peru's infectious disease problem and supported the building of a comprehensive program of tuberculosis control. Peru's program, which incorporates the WHO-approved DOT strategy of having health workers oversee the administration of drugs to patients, was credited with dramatically reducing the 
incidence of (drug-susceptible) TB between 1992 and 1996. (Ministerio de Salud 1997).

A Boston-based NGO, Partners in Health (PIH), discovered drug-resistant strains of TB in Lima in 1996, shortly after Peru's National TB Program had established an international reputation for bringing down rates for drug-susceptible TB. Peruvian authorities, guided by WHO policy, had previously treated MDRTB as a low priority and were slow to acknowledge that there was a serious problem with drug resistance. However, since 1998 the health ministry, in collaboration with $\mathrm{PIH}$, has investigated outpatient strategies for low-cost treatment of MDRTB, a regimen known as DOTS-Plus, and is now pioneering these strategies, thus laying the groundwork for interventions in other MTRTB hotspots.

I first discuss the prevalent socioeconomic forces that contributed to Peru's TB epidemics in the 1980s and early 1990s. Then I discuss how the politics and culture of biomedicine and international health development shaped responses to rising TB incidences, use of the DOT strategy, and strategies for treating MDRTB in Peru.

\section{NEOLIBERAL RESTRUCTURING AND THE COLLAPSE OF PUBLIC HEALTH IN PERU (1975-89)}

The close correlation between resurgent epidemics of infectious disease and various forms of social and economic marginalization has been well-documented (Garrett 1994; Farmer 1997, 1999a). When ethnic identity and poverty overlap in populations affected by a stigmatizing disease, as they did in Farmer's account of AIDS in Haiti (1992) and Briggs and Mantini-Briggs's (2003) account of a cholera epidemic in Venezuela, elite and public discourses about public health can take the form of ethnic profiling. In the case of the "new" tuberculosis, Gandy and Zumla (2003) have pulled together a collection of studies that illustrate how gender, ethnicity, socioeconomic class, and violence have correlated with outbreaks of TB.

Some authors have specifically looked at the relationships between the emergence of neoliberal economic policies such as cutbacks in social programs and new outbreaks of disease (See Wallace and Wallace 1998 on tuberculosis; and Kim et al. 2000). In this study I argue that the re-emergence of TB in Peru can be read in part as a biological marker for the human costs of the neoliberal movement 
that has championed economic growth at the cost of dismantled public programs and deepening urban poverty. The movement by Western bankers and politicians to promote economic restructuring in developing countries began in the mid-1970s and was formalized with the backing of the World Bank and the International Monetary Fund (IMF) in 1980.

The tuberculosis crisis that Peru faced in 1990 must be seen in relation to the prolonged economic crisis of the late 1970s and 1980s, which impoverished much of the population and decimated the public health system. In addition, the Shining Path rebellion and the military repression concomitant with the government's counter-insurgency efforts resulted in massive refugee flows into urban areas and the loss of public services to large sections of the rural countryside.

The economic crisis began with high interest rates and high oil prices in the 1970s, followed by neoliberal macroeconomic reforms that allowed the Peruvian government to restructure its external debt, conditional on currency devaluations and cutbacks in public services. Such reforms were initially put in place by a military regime following a 1975 coup d'etat against a populist reform effort; however, after 1978 the reforms became part of a package administered by the IMF. These policies, reinforced by the conservative foreign policy of the Thatcher and Reagan administrations, unleashed high inflation, reducing real wages by more than half between 1975 and 1985. The reforms eliminated trade barriers, which led to an influx of foreign consumer goods and the collapse of export revenues.

As the GDP declined and prices soared, levels of infant malnutrition increased dramatically. By 1985 food consumption had fallen by 25 percent compared to 1975 levels (Chossudovsky 1997). Popular support for the Sendero Luminoso rebellion, which originated in one of the poorest areas of the Southern Highlands, was influenced strongly by the steep drop in income and subsistence levels experienced by rural peasants (McClintock 1989).

From 1979 to 1983 the number of TB cases rose by 30 percent, making TB the fifth most important cause of death in Peru (Ministerio de Salud del Peru 1983). In an evaluation of a 12-month TB therapy regimen used by the Peruvian Ministry of Health in 1981, Hopewell et al. (1984) reported that 41 percent of patients abandoned therapy before the tenth month and that only 47 percent were cured. According to a second survey (Hopewell et al. 1985), 
cure rates improved when the health ministry adopted a shorter 8-month regimen, but the economic situation made the gains difficult to sustain. The ministry's underpaid and overworked staff were handicapped by shortages of TB drugs ${ }^{2}$ and by the increasing rural violence resulting from the Sendero Luminoso war. A shortlived respite came in 1985 with the election of President Alan Garcia of the reformist American Popular Revolutionary Alliance (APRA) party. Garcia promised to increase wages and to control inflation by reducing the country's debt service. In retaliation the IMF, the World Bank, and international commercial banks cut off all financial support to Peru. Although real purchasing power did increase over the next year, by 1987, when local business elites also "declared war on the government," hyperinflation returned and earning power once again plummeted (Chossudovsky 1997).

In 1986 the World Bank suspended a \$40 million loan for water and sewer improvements in Lima from which the Peruvian government had spent less than one-third of the funds. After the cholera epidemic broke out in 1991 a U.S. Agency for International Development (USAID) mission cited the condition of the municipal water and sewer system, noting that the cholera outbreak was "a disaster waiting to happen" (Harantani and Hernandez 1991, cited in Cueto 1997, 183). (As we will see, the highly publicized cholera epidemic shaped the political climate for infectious disease control, which later worked to the advantage of tuberculosis programs.)

Peru's health ministry was a highly politicized institution, with leadership appointed by the president and a well-established system of political patronage. David Tejada de Rivero, a former subdirector of WHO, took over as minister of health under Garcia and became a strong promoter of primary health care for the poor in Peru. His campaign, however, was resisted by many doctors and hospital administrators. After Fujimori's election in 1990 the ministry changed course, and primary health care was demoted from a guiding philosophy to "just another program." ${ }^{3}$ What health workers and officials interviewed about this period most remember is the steady decline in resources. By 1991 health worker salaries had declined to between US $\$ 40$ and US $\$ 75$ per month, and workers in both the education and health sectors were on strike. That year the country's health budget spending was less than one-quarter of what it had been in 1980 (Cueto 1997).

Continued civil war eventually closed down scores of rural clinics, further damaging morale. After the collapse of the public 
health infrastructure in the selva (rainforest) region there was a resurgence of malaria, dengue, and leishmaniasis (Chossudovsky 1997). The only health program that kept functioning countrywide was vaccination against childhood diseases, thanks to intervention by UNICEF and WHO, and an accord with armed rebel groups, permitting vaccination in regions that they occupied.

Chronic undernutrition also contributed to the rise in tuberculosis during the 1980s. More than 83 percent of the population failed to meet minimum calorie and protein requirements by 1991, and the national rate of child malnutrition rose to the second highest in Latin America (Chossudovsky 1997). Only half of TB patients received treatment in the late 1980s, and half of those abandoned treatment and were lost to follow-up. Only one-fifth of the country's clinics even offered TB treatment in 1989, and its information system for TB was in disarray. ${ }^{4}$

This was the situation when Peruvians elected Alberto Fujimori on a populist platform. Once elected, and after consulting with IMF advisors, Fujimori reneged on his promises of improving quality of life for the majority and instituted his famous "Fuji-shock," further compressing wages and social expenditures, and laying off more public-sector workers. Prices shot up overnight. Thousands of soup kitchens sprang up in pueblos jovenes (urban squatter communities) as families began pooling resources to make ends meet. To give just one example, the 30 -fold increase in cooking oil costs in Lima made it difficult even for the middle class to boil water or cook food - one of a combination of factors thought to have contributed to the 1991 cholera epidemic (Chossudovsky 1997), which drew international attention and overshadowed other health problems.

As cholera was being brought under control, a group of Peruvian physicians met with Fujimori about the country's TB problem and convinced him to make tuberculosis a national priority. The improvements in tuberculosis control from 1992 to 1996 paralleled the restoration of resources to public health in general following the 1992 capture of Shining Path leader Abimael Guzman, effectively ending the civil war. Many health policy observers believe this initiative, uncharacteristic for the neoliberal regime that had scoffed at most anti-poverty programs, was influenced by the bad publicity the country received during the cholera epidemic. One factor may have been a series of large street demonstrations staged by TB patients and activists calling for access to anti-TB drugs. The risk of contagion may have been seen as a potential threat to tourism 
and foreign investment at this key moment, when the government sought postwar funding for reconstruction.

Peru was in good company in 1990. In many countries, including the United States, public health programs had been dismantled during the 1980s (along with other social services) in the name of making government more efficient and diverting capital to private-sector concerns. The timing of the discovery of TB epidemics in New York City and other U.S. inner cities in the early 1990s paralleled that in Peru. This accounting of the socioeconomic contributors to TB epidemics illustrates why, in the words of one Peruvian health expert, resurgent tuberculosis is a "social disease."

The role of poverty in the epidemiology of TB is an old story. And the helplessness that many health professionals feel in the face of rising inequity has contributed to what some authors have called "public health nihilism" —or pessimism about the possibilities of controlling TB (Fairchild and Oppenheimer 1998). But, significantly, it is not only the incidence of the disease that creates epidemics but also the incidence of public health funds. A more accurate account of the relations between poverty, public health programs, and tuberculosis should acknowledge that poverty is not an unvarying fact of nature but, rather, is created by humans in the form of economic policies (often backed by structural violence) that sacrifice the health of the most vulnerable in order to divert funds to profit the least vulnerable (i.e., the privileged classes) - a process that is as transnational as is the epidemiology of tuberculosis.

TB CONTROL IN PERU, 1992-99: "THE PROGRAM IS GOOD, BUT THE DISEASE IS BETTER"

Ironically, the availability of more effective drugs for tuberculosis in the developed world did not translate into better disease control in poor countries; rather, efforts to fund the adequate global distribution of TB drugs languished, and, in the 1970s and 1980s, the apparent success in controlling TB in the United States and Europe created complacency in the international health community. The lack of access to quality medical care (and continuity of care) in the Third World contributed to three decades of a global tuberculosis epidemic that has resulted in millions of preventable deaths and the outbreaks of drug resistance that plague us today. Fortunately, during the late 
1990s the decision of the World Bank to focus on diseases causing disability during adults' productive years (an offshoot of the bank's 1993 introduction of economic criteria to health decision making) made TB programs an international health priority.

Physicians who had a strong commitment to international public health played a leading role in reforming and promoting Peru's tuberculosis program, which includes clinic-based DOT. However, classic problems of inadequate funding, professional dominance, bureaucratic intransigence, and government arrogance toward community-based approaches have continued to plague Peru's TB program and to interfere with a rapid response to the growing problem of drug resistance in urban areas. It is especially ironic, according to observers, that the relative success of the DOT program after 1992 may have contributed to making physician leaders complacent and slow to acknowledge the problems associated with the discovery of MDRTB strains in Lima in 1996.

Before 1990 the Peruvian health ministry estimated that 300,000 patients nationally had active disease and that half of these were going untreated. There was no national system to track the many non-compliant patients. Dr. Cesar Bonilla, a pneumonologist at Daniel Carrion Hospital in Lima, recalled that "TB wasn't really seen as an emergency in the daily work of most health workers. Many had a fatalistic view-believing tuberculosis couldn't be cured as long as poverty persists—so what's the point of trying?"

Dr. Pedro Suarez, who directed Peru's National Tuberculosis Program for most of the 1990s, is widely credited with building a critical mass of supporters within the medical community and successfully lobbying the Fujimori administration to back the program. Beginning in 1990 Suarez invited scores of hospital-based physicians and university-based professors to meetings on tuberculosis held all over the country. The doctors were required to attend three to four meetings each year, where they dealt with both theoretical and clinical issues. At the end there were 200 to 300 health workers (from all levels) attending each meeting. "We felt there was finally a consensus that TB could be cured. We wanted to close the breach," recalled Suarez.

Daniel Carrion Hospital became the center for training. According to Bonilla, who took part in the project, "it was good that they started with physicians because the problem [with TB] had been the doctors, not the nurses. Many times doctors acted as obstacles to well-trained nurses. The specialists, particularly, had the attitude 
that nurses had to follow their orders, and even with a competent nurse, often the doctor wouldn't let her do her job."

Young MDs were especially important, according to Bonilla, because they criticized "false prophet" physicians who always talked "from [their] experience," relying on anecdotes. He continued: "We worked more from concrete investigations, and not only from studies done in the United States. We did studies of the situation in Peru. We adapted foreign models, but with a Peruvian slant. Our people became proud to work in such a program. Before this, to work in tuberculosis was to be marginalized."

Asked what he thought had convinced Fujimori to make TB a priority, Suarez responded diplomatically, calling the program "part of [the government's] struggle against poverty." He credited support and technical help from WHO as well as the fear of contagion in the aftermath of the cholera epidemic. One health ministry physician speculated that the Fujimori administration's support of TB control was a response to protests about hunger and health conditions in Lima's pueblos jovenes. Fujimori responded to these protests because he "needed to give the impression internationally that he was very concerned about poverty."

After 1992 the state assumed almost all costs of TB medicines and a nation-wide clinic-based DOTS (the " $\mathrm{S}$ " refers to "shortcourse" therapy) program was put in place. The network of regional TB laboratories expanded from 13 in 1991 to 57 in 1996, while the number of cases dropped from 300,000 to around 47,000. In 1996 Peru's National Tuberculosis Program was honored by WHO as a model DOTS program, and it continues to receive high marks from many public health experts in Lima for bringing down the incidence of TB in only four years. In 1999, when these interviews were conducted, it also stood out as one of the few programs in the ministry with a reputation for efficiency.

Even with the model DOTS program in place, however, the prevalence of TB remained among the highest in Latin America at 216 cases/100,000 pop (Farmer 1999a). Some researchers had complained that the health ministry's reporting methods, which combined statistics from zones with disparate incidences of TB, tended to mask the concentration of TB in Lima's poor shantytowns (Sanghavi et al. 1998). And although the TB budget in Peru increased each year between 1992 and 1996, it stayed fixed after that, which meant a gradual decrease in real dollars allocated to the program. 
Spiraling unemployment had hamstrung the poor and middle classes in Peru since the 1990 "Fuji-shock," but a further economic downturn in mid-1998 added insult to injury. Neoliberal proposals to reform public health while reducing government health spending generated widespread skepticism among public health experts. And for good reason. Even several years after the restoration of health services funding, Peru's basic health indices remained among the lowest in Latin America (Cueto 1997).

Dr. Emma Rubin de Celis, a professor of health policy in Lima, blamed neoliberal reforms for pushing public health physicians to maximize the number of consults and to process patients too rapidly: "Patients are urged to help finance care, even to the extent of having family members of [poor] patients clean the hospital." ${ }^{\prime \prime}$ Meanwhile, the value of physician and nurse salaries dropped, and the Ministry of Health began to contract with many physicians instead of hiring them for permanent positions-a practice that, according to Rubin de Celis (who teaches at the Cayetano Heredia University), has resulted in high turnover and poor continuity of care.

A major tenet of neoliberal health reform in Peru has been to limit state responsibility to promotion and prevention, leaving most medical treatments in the private realm, with the costs falling on the individual patient (Kim et al. 2000). In a colloquium on health reform at the Cayetano Heredia School of Public Health, the Health Ministry was represented by Dr. Ricardo Corcuera, who presented a "Power Point" slideshow that celebrated the transition from an "old concept of the state" to a new paradigm. Instead of the old paternalism and institutional dominance, he touted reforms, which were explained on slides illustrated with inspiring landscapes, involving the "wonders of new technology" and "inevitable globalization." This "new" state would emphasize efficiency, production, high quality, and individual choice. His audience, mostly public health faculty, seemed bored and followed up with a series of pointed questions about shortages of funding and growing inequities. $^{6}$

The couching of public health problems in terms that blame individual victims (e.g., for poor hygiene or poor compliance with treatment protocols) was prevalent within Fujimori's government even during the cholera epidemic, when public health messages emphasized hand-washing and ignored the systemic causes of the outbreak (Cueto 1997). The state guaranteed direct health care 
services only to the very poor, according to Dr. Julio Castro, a private physician and former legislator with the APRA party. The problem, he said, is that studies show that poor families make food and housing their top priorities and tend to neglect health problems until they are serious. ${ }^{7}$

Professors of public health at Cayetano Heredia University like to quote a phrase coined by Castro to describe Peru's TB program: "The program is good, but the disease is better." Asked what he meant by this, Dr. Castro said, "The government is content in having a 'good program' for control of TB, but they are measuring the program, not the size of the TB problem. And the international agencies are content with this approach also." He blamed neoliberal policies for the continuing high rates of TB. "At the base of the problem is unemployment," said Castro, noting that since 19901.5 million jobs had been lost in Peru.

Dr. Jose Santos, a 20-year veteran with the Ministry of Health, spent much of his time at ground-zero of Peru's TB epidemic, moonlighting in NGO-run health posts in northern Lima's shantytowns where he was working during our interview. While he talked about TB policy he examined a thin toddler with a runny nose, who had arrived at the clinic wrapped in a shawl slung over the shoulder of her mother, a small Indian woman, who, like tens of thousands of Peruvians, recently immigrated to the outskirts of the capital fleeing rural poverty. Santos complained that for years he had watched patients relapse after completing the ministry's TB treatment program. With their energy sapped and their families' savings depleted, they go seeking in vain for expensive second-line antibiotics they cannot afford. Santos claims he predicted that resistance to tuberculosis drugs was coming years ago. "The Ministry battles the bacillus, but it's the socioeconomic conditions of the people that cause $\mathrm{TB},{ }^{\prime \prime}$ he said.

"The ministry ought to ask: 'If we have such a good program, then why do we have so many patients?"' Santos argues that even patients who are cured of active TB will get sick again if they continue to be malnourished. He pointed to the growth charts for the toddler and her brother, who were once dangerously malnourished but who had steadily gained weight under the NGO's food supplement program. Santos has been a long-time advocate for better nutrition supplements for patients during the entire course of their treatment. "You have children with TB and the ministry has resources for pills, but not for food. What craziness is this!" 
Similar recommendations came from a 1998 study of the National TB Program. The study, carried out by the Proyecto Salud y Nutrición Básica (PSNB), found that patients in Lima, where the TB epidemic is most concentrated, had only received food supplements twice in the previous year and that one-third of patients interviewed had never received food (PSNB 1998). Sources in the National TB Program at the health ministry confirmed that food supplements were no longer available for most patients, a problem that was blamed on cuts in foreign aid food programs. Such drops in funding, including cuts in the Title II food program of USAID, had forced many of Lima's "popular" kitchens to close. Whereas in 1993 about 7,000 such soup kitchens were in operation, by 1999 the number was closer to $500 .{ }^{8}$ Malnutrition was not the problem it was in 1990, but in 1996-97 one-quarter of Peruvian children under the age of five remained chronically undernourished, with anemia affecting 60 percent of those under two years of age (Cortez and Calvo 1996-97), so it is likely that inadequate nutrition continued to contribute to the incidence of tuberculosis in Peru. The PSNB study found that, despite the ministry's efforts, TB care was not integrated with other health services and that patients who came to a clinic with other health problems often didn't get referred for TB symptoms. One of the study's strongest recommendations was to strengthen the clinic-based DOTS program through the use of community-based promoters. To its credit, the health ministry does recruit lay health promoters from communities that its clinics serve; however, the dedication of such people to these unpaid positions varies greatly, and the researchers found that, at most urban ministry clinics, promoters played little role in TB care. Partly as a result of this, home visits to follow up on patient contacts who might be infectious tend to be perfunctory. One-third of patients interviewed reported that they had never been seen by a social worker. The study also found that the DOTS goal of supervised therapy was not met in many rural areas, where clinic staff members give patients a week's supply of pills at each visit.

A community health worker with an NGO in a poor barrio of northern Lima agreed with the PSNB findings. She noted that one reason so many $\mathrm{TB}$ patients become non-compliant is because of the inconvenience and cost of taking public transport to a health ministry clinic in order to receive their pills: "Many enter treatment for two months and then disappear when they feel better because they have kids and have to work. If someone has to be at work 
by 7:00 AM, they can't just leave and go to the clinic when it opens at 8:30. Even if they did they'd find dozens of patients waiting to be seen and they'd have to wait."

Interviews with MDRTB patients supported her assessment. Edith de la Cruz, 25, who was diagnosed with drug-resistant TB in 1996, lives in a northern barrio of the city. She was treated for a year at a government clinic for drug-susceptible disease, which involved a daily two-hour bus journey to and from the clinic to receive her pills. Bus fares ate up one-eighth of her daily wages, cutting heavily into an already tiny budget for food and other necessities. At the end of a year tests showed that she was still positive for TB. Edith reckons she caught the deadly strain of bacillus from her uncle, Raymundo, an alcoholic who has since died. Raymundo had dropped out of the government TB program only four months after beginning treatment, complaining that the pills upset his stomach.

Francisca Poma, 54, another MDRTB patient I interviewed, lost four adult children and one grandchild to drug-resistant disease. Speaking to me in her two-room, open-sided shanty carved out of a rocky hillside, Francisca was left caring for four grandchildren after their parents succumbed to the disease. Though renowned as a hard worker, Francisca lost her meager income from selling newspapers when she became too ill to walk or to even pick up the youngest baby. Getting to the clinic became impossible, and there seemed little point after the health ministry doctor told her they had nothing to offer her unless she could raise the money for expensive second-line antibiotics.

Hearing that I was studying TB, even my cab driver had a story to tell. He revealed that he had an undernourished daughter in the hospital with TB-like symptoms. "Government clinics only offer poor service," he claimed. "They always tell you there are no more appointments, and you have to come back another day." He complained bitterly about medical costs, saying he had to go that very night to beg an administrator at the hospital to give him more time to pay a debt.

The lack of focus on community-based health work in Lima reflects, in part, the reorganization of the health ministry after Fujimori's election. Dr. Cueto, a public health historian at Lima's Instituto de Estudios Peruanos, said that, while the 1980s had seen growth in primary health programs, after 1990 "the communitybased folks lost ground to vertical programs. You have to remember Fujimori was trained as an engineer. He favored single-factor 
technical interventions and didn't tend to worry about those who got left out of the plan." Cueto noted that, during the late 1990s, the Ministry of Health tended to avoid encouraging public criticism and discussion of wider health problems (like those associated with what caused the cholera or TB epidemics).

The tendency to avoid dealing with unpleasant realities that challenge the official description of any given problem has peculiar consequences. A disturbing finding of the PSNB study was that some health ministry clinics kept a second set of records for patients who dropped out of $\mathrm{TB}$ treatment and then re-entered the program at a later date. Records for these "problem" patients were hidden and were not reported to the central office, raising questions about the true failure rate of the National TB Program, which was officially reported at 15 percent (PSNB 1998). "These patients are a headache for the nurses. They don't like to deal with them. Many are addicts or drunks, so they try to turn them away. They mess up the statistics. Everyone thinks they will fail the program again," explained Beth Yeager, a researcher on the study. In later interviews, two physicians with long-term experience with Peru's National TB Program made similar claims that records for patients who abandoned treatment were not included with official government statistics.

Although Suarez attended planning meetings for the PSNB study, a researcher who worked on the project complained that he showed no interest in the findings. When I asked him about the PSNB findings he dismissed the study as irrelevant. The PSNB recommendation to strengthen community-based health work, however, is in line with the suggestions of many TB specialists who maintain that DOT is only one element of a successful TB program (see, for example, Lerner 1993; Farmer and Nardell 1998; Farmer 1999b; Bayer 1998).

MDRTB AND THE LIMITS OF INTERNATIONAL PUBLIC HEALTH MODELS

Another Lima-based NGO played an important role in discovering and characterizing the city's TB drug resistance problem. Patients with MDRTB were first identified in early 1996 in Carabayllo, a poor barrio of northern Lima, by Socios en Salud (SES), a health project affiliated with Boston's Partners in Health (PIH). An earlier 
survey of Latin American MDRTB clusters by Laszlo and Kantor (1994) had also identified a poor neighborhood on the outskirts of Lima as having the highest level of drug resistance in the survey, at 54.5 percent of isolates. ${ }^{9}$ Since physicians at PIH had experience with TB and drug-resistance in other settings, they undertook drug susceptibility testing and began to treat MDRTB patients in northern Lima shantytowns (Farmer and Kim 1998; Farmer 1999a and 1999b; Becerra et al. 2000).

In May 1996 Dr. Jaime Bayona, medical director of SES, first approached Peru's Ministry of Health for help to obtain expensive second-line drugs to treat ten MDRTB patients. The ministry declined to participate. In an interview, Bonilla, speaking for the health ministry, explained that in 1996 government health authorities elected to concentrate their limited funds on drug-susceptible TB: "The way to stop MDRTB is to prevent it. This is a poor country, and there are low success rates for treating MDRTB everywhere."

The potential costs for treating MDRTB were indeed formidable. In the program that PIH/SES developed to treat MDRTB patients, the estimated costs in 1999 to cure a patient with resistance to two drugs ran around $\$ 1,000$, but patients resistant to four to six drugs might cost between $\$ 5,000$ and $\$ 8,000$ each. In contrast, the cost of curing drug-susceptible TB in Peru was only about $\$ 50$ per patient. ${ }^{10}$

Dr. Bayona of SES and Drs. Paul Farmer and Jim Yong Kim of PIH continued to meet with Suarez, and they shared with the health ministry their data on rates of drug resistance that SES was encountering in northern Lima. Of 160 TB patients tested, who had not been cured in the National TB Program, 93.8 percent had active MDRTB (Becerra et al. 2000). More than two-thirds of the drugresistant patients that SES identified were resistant to all four of the drugs used in Peru's National TB Program (Becerra et al. 2000). Many had been treated with an incomplete regimen of the drugs used in the country's "standard" treatment protocol prior to 1992, and that, according to Farmer (1999b), is how most acquired their initial drug resistance. Later, after the reforms, patients who relapsed were re-enrolled in the health ministry program and were retreated with the same drugs, plus one additional drug. The PIH/SES researchers became convinced that WHOapproved DOTS strategies of re-enrolling patients who had formerly dropped out of therapy and treating them with the same 
drugs a second time was actually amplifying drug-resistance (Farmer and Kim 1998; Becerra et al. 2000). Although health ministry officials continued to maintain that the MDRTB threat was minimal, they agreed to refer patients from northern Lima who had abandoned TB treatment in health ministry clinics to the PIH/SES program.

Significantly, it was only in 1997 that the health ministry in Peru began using a four-drug retreatment program for patients who had failed the initial regimen. Before that, all patients who had failed or abandoned treatment and re-entered the program were retreated by the same drugs they had initially received-a practice well known for generating drug resistance.

Marcos Espinal, head of communicable diseases at WHO, said that the Peruvian health ministry had done the right thing from a public health standpoint in declining to treat MDRTB patients. In a May 1999 phone interview Espinal said: "Most cases of TB in the world are drug-susceptible, it would be a major mistake to give the message to developing countries that MDRTB is a higher priority." He maintained that the SES model of community-based treatment was expensive and too dependent on close physician oversight to be replicable on a larger scale.

Health policy analysts in Lima, however, note that issues of prestige may have also been a factor in the slow health ministry response. When confronted by the $\mathrm{PIH} / \mathrm{SES}$ evidence of drug resistance, officials in the National TB Program were basking in the approval generated by WHO's 1996 designation of Peru's TB program as a model for the Third World, and they tended to dismiss criticisms of the program.

Realizing that the cost of second-line drugs would rapidly become prohibitive for their NGO undertaking, Farmer and Kim began lobbying WHO, USAID, drug companies, and other international health institutions to draw attention to the need for affordable second-line drugs and international funding for MDRTB. PIH hosted several small conferences on drug resistance and pulled together a multi-institutional working group on MDRTB to advise international agencies. Their efforts were boosted when a new survey of drug resistance in the world commissioned by WHO and the International Union against Tuberculosis and Lung Disease was published in 1998. The survey, conducted from 1994 to 1997 in 35 settings found drug resistance in every country and region surveyed, and identified MDRTB "hot zones" in Russia, Estonia, 
Latvia, the Dominican Republic, and Argentina (Pablos-Mendez et al. 1998). Peru also ranked high on their list. WHO estimates that 50 million people may already be infected with drug-resistant TB strains, and the problem is growing rapidly, with drug resistance developing in 10 percent of the 8 million new TB infections occurring each year.

In fall 1998 the Peruvian government, with WHO approval, began its own pilot program, using a standardized drug regimen to cure drug-resistance, which was designed to cost no more than $\$ 1,500$ per patient. "We became convinced we had to do something because each of these patients was a source of disease transmission," recalled Bonilla.

There were big differences between the health ministry's model and the PIH/SES model for treating drug-resistant TB. The medical team from the two NGOs found that they had to tailor regimens for no less than 34 drug-resistance profiles in the cohort of patients (Becerra et al. 2000). To manage this, SES health workers met daily, with follow-up communication by e-mail with Boston-based PIH, to monitor each patient's progress and to adjust dosages and drugs as indicated. ${ }^{11}$ Although potential patients for the health ministry trial were given drug susceptibility tests to determine whether they had drug resistance, ${ }^{12}$ in initial trials the ministry did not use the test results to tailor treatments to individual resistance patterns, as did PIH/SES. Instead, the ministry sought to test a more affordable, and replicable, "one-size-fits-all" approach to therapy. A health worker in the ministry's TB division attributed the decision not to individualize treatment, in part, to the difficulties of training doctors and nurses in a system in which so many worked on contract and often had to move from one post to another. In interviews several TB experts with experience dealing with drug-resistance expressed concern that, given the variety of drug susceptibility profiles (86 percent of the patients in the ministry trial were resistant to three or more drugs), ${ }^{13}$ the ministry's one-size-fits-all drug treatment plan would not be effective against MDRTB.

By mid-1999 it was clear that the PIH/SES treatments were curing drug-resistant TB. At that time PIH/SES reported that 85 percent of the 80 drug-resistant patients who had completed individualized 18-to-24-month treatment protocols had remained smear and culture-negative. ${ }^{14} \mathrm{~A}$ few months later, as the Peruvian health authorities analyzed the health ministry's trial data, it appeared that some of the fears the NGO physicians expressed about the 
government trial were valid. Less than one-third of the first cohort completing the ministry's trial were cured. ${ }^{15}$ Since then the ministry has joined forces with the PIH/SES team to treat MDRTB in Lima, an effort that has recently been greatly aided by new funding from the Bill and Melinda Gates Foundation, which allowed the program to be expanded to bring over 800 patients from all districts of the capital into treatment. In late $2002 \mathrm{PIH}$ reported that the rates of "likely cures" for the program's first 367 drug-resistant patients ranged from 68 percent to 86 percent, depending on patients' levels of drug resistance. ${ }^{16}$

The determination that a standardized "one-size-fits-all" regimen results in such low cure rates for MDRTB patients presented a special challenge to WHO's communicable disease program. Another major challenge to international protocols was illustrated by the differences in outpatient care in the two trials on Peruvian patients. In order to treat MDRTB, patients must take highly potent drugs for up to 18 to 24 months; these drugs cause a myriad of side effects, from upset stomachs to dizziness to loss of appetite and generalized aches and pains. Although both the PIH/SES and the initial health ministry trials for treating MDRTB were outpatient programs, the levels of community-based services differed greatly. To deal with the serious side effects of the drugs, the PIH/SES program put great emphasis on training full-time, salaried health promoters who spend most of each day visiting patients' homes, where they observe them take their drugs, talk with them about symptoms, and advise them on how to deal with problems. Promoters also work with family members to establish a support system for the sick person.

I spent a day accompanying Hildo, an SES promoter, on his rounds. The first activity on most days at SES involves a roundtable meeting of the promoters and nurses to discuss patients' progress and to talk over approaches to solving problems. A key issue for many patients is loss of appetite, and one of the second-line drugs is famous for causing stomach pain and gas. The promoters experiment with crushing the larger pills and offering patients milk or juices to drink with them.

After the gathering we caught one of the buses that runs up and down the crowded, dusty highway that separates the heavily populated Carabayllo hillsides from the narrow coastal plain. Getting to Edith de la Cruz's modest cinderblock house involved leaving the road and hiking up a barren hill to a cluster of houses perched 
on a ridge overlooking the busy thoroughfare. At the top Hildo struck out to the north, leading me several blocks along a dirt alley lined with tiny mud-brick huts. We passed dust-covered children playing in the alleyway and picked our way over used tires and sleeping dogs. The cool shade of Edith's house was a welcome respite.

A pretty woman with shoulder-length brown hair, Edith is an SES success story, having tested serum-positive at last after nearly two years of the SES protocol, following a year of failed treatment in the national TB program. But access to the expensive second-line antibiotics alone would likely have not saved her life. The powerful drugs made her so sick with nausea, vomiting, headaches, and weakness that she came close to quitting the regimen.

"Sometimes I wanted to stop because I felt worse off than before I started taking the pills. I lost my appetite. All I wanted was a bit of salty cheese," she recalled, showing me the tiny room, mostly filled by a single bed that had been the extent of her world for several months during the therapy. "My mother insisted I eat a little fruit, and I learned that it was better to eat something with the pills or they were worse on the stomach. The Socios promoters cared a lot about my symptoms. They helped me with transportation, and brought me fruit to make juice to take with my pills."

SES also provided the family with extra food during the early months of treatment, a common practice when patients are underweight. Hildo worked out an arrangement with Edith's mother to oversee her drug doses in the evenings, and once she began to regain her strength and her serum tests for the bacillus became negative, he arranged for her to do volunteer work with kids in the community - a strategy that he said often helps patients feel useful and distracts them from their personal health problems. Later that week I accompanied an SES psychologist and a group of about 25 patients on a trip to the zoo. She said that depression and suicidal ideation were common in poor MDRTB patients, most of whom had previously been told by doctors that they would die of the disease if they could not afford the second-line drugs. She had found that outings and other activities gave the patients a chance to socialize and helped take their minds off their conditions.

As noted earlier, in her first round of TB treatment, before she was known to have drug-resistant disease, Edith had spent two hours each day traveling to a Ministry of Health clinic where a 
health worker watched her swallow her pills. When the ministry began its initial trials for treatment of MDRTB patients in 1998 it depended on this model of clinic-based DOT, relying on the MDRTB patients to travel to the closest clinic each morning to get their drugs. Support services such as food supplements were provided at the clinic. Some ministry clinics had volunteer health promoters who went to look for patients who missed treatments; however, as the PSNB study shows, the effectiveness and coverage of the ministry's health promoter network was spotty.

Aware of the many side effects of the powerful drugs used to treat MDRTB, SES's Dr. Bayona worried that the lack of community-based outreach and support in the health ministry program would lead to a high drop-out rate, which could amplify existing resistance. This would be a death sentence for such patients, and put their families and friends at risk. He noted that some patients simply wouldn't be able to visit the clinic daily: "If you have MDRTB are you going to sit in your house or are you going to go to work? You have to support yourself. People with MDRTB are working as waiters, mechanics, bus drivers, etc. and they are spreading [drug-resistant] disease."

Dr. Robert Gilman, an American physician who does research on TB through an affiliation with PRISMA (a Lima-based health NGO), concurred with Bayona about the long-term risks associated with MDRTB patients going untreated. He cited the WHO estimate that a drug-resistant patient who remains infectious continues to infect about ten other people each year, one of whom, on average, will come down with active MDRTB. Gilman, who teaches at Johns Hopkins School of Hygiene and Public Health in Baltimore, Maryland, then made a chilling observation: "You have to remember that the other nine who are infected with MDRTB, but who don't get the disease right away, may get it later if their immune systems become weakened by malnutrition or other illnesses" (emphasis added). In a country with the malnutrition and poverty rate of Peru, that prospect seemed daunting indeed.

The dilemma that MDRTB poses to international health experts is a Faustian one. If the international spread of MDRTB is to be checked, then TB specialists may have to turn to more community-based and education-intensive approaches that are costly and difficult to implement. Dr. Dixie Snider, of the CDC's Division of Tuberculosis Control, pointed out that, from an economic standpoint, international agencies did not have a full commitment 
to curing drug-susceptible TB. It was not until the early 1990s that the resurgent TB epidemics in the United States and changes in health priorities at the World Bank drew more funds to international TB, boosting the promotion of DOTS in poor countries. At the end of the decade, less than one-fifth of TB patients globally had access to DOTS programs. ${ }^{17}$ Without additional funds and a drastic drop in prices for the necessary antibiotics, most experts found it hard to imagine how MDRTB could be dealt with on a global scale. The rub, according to Snider, was that, "where there's a large pool of MDRTB and drug-resistant patients enter existing TB treatment programs without being cured, even good TB programs lose effectiveness. It hurts their reputation with the public."

For this reason, the physicians at PIH elected to undertake a rare advocacy effort with governments, agencies, drug companies, and private foundations, promoting their approach to treating MDRTB, which they designated DOTS-Plus, and seeking increased funding and cheaper prices for second-line TB drugs. Regrettably, the United States, one of the countries best able to fund new international health efforts, had shown relatively little leadership on the global TB problem. In 1993, just as the CDC and WHO were gearing up to confront resurgent TB, USAID had cut its entire overseas budget for TB control (Garrett 1995). New policies adopted by the Clinton White House in 1996 to deal with emerging disease threats focused heavily on surveillance for TB at the country's borders as well as education of travelers, but they failed to address the core problem of financing responses to the global epidemic (Lederberg 1996).

While PIH physicians Farmer and Kim emphasized the humanitarian argument for curing MDRTB, they found that they made more headway with international health authorities once they began pointing out that, in a hot spot for drug resistance, a DOTS program for drug-susceptible TB may, perversely, amplify resistance when the more marginalized patients drop out of the program after their symptoms improve, only to reenter it once they relapse. ${ }^{18}$ Kim and Farmer's promotion of their DOTS-Plus approach began to be taken seriously in 1998 when they were commissioned to aid in an initiative of George Soros's Open Society Institute to develop a treatment program for what is thought to be the largest MDRTB hot spot in the world-the gulag of Russian prisons, where 30,000 people were thought to be 
infected with drug-resistant strains. A year later Farmer and Kim published a massive report on the global impact of drug-resistant TB, which gained international publicity.

A major breakthrough in lowering drug prices came after Kim convinced TB specialists at the WHO to put the second-line antibiotics on an annex to its essential drug list, and establish a committee to oversee their distribution. This helped to create a market and for the drugs. While Kim focused on the WHO, Farmer lobbied Eli Lilly, the pharmaceutical company supplying PIH with capreomycin, to lower its prices. The combined approach bore fruit. By 2000 costs for second-line drugs purchased through this system had dropped more than four-fold, compared to prices paid just four years earlier (Kidder 2004, 173).

The efforts of the PIH doctors were boosted enormously later that year when PIH, Harvard Medical School, and several other organizations received $\$ 44.7$ million in funding from the Bill and Melinda Gates Foundation to treat MDRTB in Peru, Haiti, and the former Soviet Union. The Gates Foundation also issued new funding for research on TB drugs and diagnostic tests. ${ }^{19}$

\section{REFORMING PUBLIC HEALTH: ADVOCACY, OUTREACH, AND COMMUNITY-BASED CARE}

As we have seen, both the spread of drug-resistant TB in Peru and programs to cope with this epidemic must be interpreted in light of the country's recent history of political and economic turmoil. In the 1970s public health reforms were undermined, initially by military intervention, then, in the 1980s, by economic intervention spurred by international lenders (and national business elites). In the 1990s a strong program for fighting TB in Peru grew out of the efforts of a group of reformist physicians, but the critical ingredients of funding and political support were byproducts of President Fujimori's efforts to restore Peru's image in the eyes of tourists and foreign investors after the Shining Path war and the embarrassing cholera epidemic.

Unfortunately, one thing public health programs everywhere have in common is financial instability over time. The tendency of policy makers to discontinue disease-specific programs after the problem is contained has been dubbed the "U-shaped curve of concern" (Reichman 1997). With regard to Latin America, Cueto 
(1997) has described long-standing patterns of health services being funded in spurts: funding increases when an epidemic occurs, then declines when it abates. Despite the substantial improvements in incidence of drug-susceptible TB in Peru from 1992 to 1996, during my visit to the country most experts with whom I spoke in the public health community worried aloud that, given persistent high poverty and unemployment, and continued neoliberal pressures to reduce government commitments to health, gains will not be sustainable.

The bright side of this story is that new funding for the trial project for curing MDRTB begun by PIH may make Lima one of the few success stories among the world's TB drug resistance hot spots. With luck, due to this celebrity, the continued attention to the country's TB situation may help keep the budget for the national TB program healthy.

WHO, lacking a large budget or any regulatory authority, relies on the reputation of its professional medical staff, along with a limited capacity to fund specific programs, for its influence and leverage in member countries. WHO's capacity to monitor countries' DOT programs for TB is limited, and the organization has played a relatively minor role in assisting ministries of health with strategic planning or management of health services. ${ }^{20}$

Central to sustainability in any health program is strong advocacy on the part of public health authorities to maintain support for prevention and screening infrastructure as well as for rapid responses to rising rates of disease. We have seen how critical a role advocacy played in Peru-where street protests by TB patients and activists drew public attention, while Dr. Suarez quietly lobbied Fujimori to establish Peru's National TB Program. Similarly, advocacy from PIH in the late 1990s was a key factor in persuading WHO and Peruvian authorities to confront the problem of drug resistance.

Ideally such advocacy would originate with public support for health programs. Socios en Salud assisted, for example, in organizing a TB patients association that advocated for treatment of drugresistance in the late 1990s; however, in an impoverished setting and with a disease as stigmatized as tuberculosis, such public participation is difficult to sustain. In addition, publicity about drug resistance in specific populations can lead to public profiling, which exacerbates stigmatization and makes tracking cases and treatment more difficult. 
A lack of public education and awareness about the relations between poverty and disease is at the heart of the problem. In Peru's National TB Program workers lament the lack of resources to distribute public information on TB. Other than banners over a couple of highways, there was little evidence of government outreach to the public. Dr. Pablo Campos, who studies infectious disease at Cayetano Heredia University in Lima, noted that this is especially risky in a country where so many people are illiterate. "There is no popular concept of TB or AIDS in Peru," he said, but he expressed hope about a new program to incorporate health education into the schools. At Daniel Carrion Hospital, Bonilla worried about the effect of lack of public awareness on TB case finding: “The extreme poor don't go to clinics, and the middle class has a very low awareness of TB. Yet as the program progresses, we see more and more atypical patients. It's not just pobrecitos who come into our clinics with TB nowadays."

Hence, the "signal" function of calling attention to an acute problem falls to health professionals. Advocacy by health professionals is not, of course, a substitute for epidemiological data, but it may serve as an impetus for doing the necessary studies and acting on the findings. However, in a situation that involves little pressure for accountability, such as that in which Peru's National TB Program found itself after receiving WHO recognition in 1996, conservative interpretations of epidemiological risks often become substitutes for evidence-based decision making. PSNB's critical study of Peru's clinic-based DOT program such a short time after WHO accolades also raises questions about the criteria used by WHO to evaluate DOT initiatives in developing countries. Are the shortcomings of clinic-based DOT glossed over in the name of maintaining goodwill with national leaders? One of the lessons of the SES approach to communitybased DOT and MDRTB is the importance of flexibility. It is crucial to be able to accommodate patient differences with regard to side effects related to the second-line drugs as well as to be able to adjust the regimen so that patients are able and willing to continue treatment.

Many Peruvian health workers and experts whom I interviewed had concerns about the level of complacency within the National TB Program but were reluctant to advocate for change locally, which may have reflected their fears that-given the recent neoliberal zeal to cut social programs-critical debate about TB services 
would upset the applecart of a "good program" (even though, given Peru's poverty and MDRTB problem, the program may not have been good enough).

Some tuberculosis experts interviewed for this study expressed discomfort about advocacy in the public arena, noting that it often involves overstating one's case, using hyperbole, and confronting authority-positions that seem at odds with scientific notions of objectivity. Advocacy around new TB epidemics was also slow to develop in wealthy countries. It was only after outbreaks of drugresistant TB in several U.S. inner cities in the early 1990s that the U.S. CDC developed materials on how to better advocate about health concerns with politicians, the press, and the public.

One of the best approaches to public education and to solving the ongoing problem of tracking TB cases in poor neighborhoods with limited professional staffs involves following the PSNB recommendations (and the SES example) and putting more resources into community-based health outreach work. Dr. Campos agreed: "We need to redefine the roles of health promoters. They should be more involved in promoting the rights of the patient instead of working as medical assistants."

Academic proposals for a more "integrated" public health system dovetail with the goals of community-based DOTS, particularly the heavy emphasis on education (of health workers and the public) and on improving communication and participation both within the health system and with patients. Such programs require investment in people along with a recognition of longer-term futures and a more complex social and epidemiological big picture than is acknowledged in individualized, curative care models or in neoliberal political ideologies.

The solutions are necessarily social ones, for tuberculosis is a social disease. It is spread by poverty, and, by striking men and women in their prime, it creates poverty. It is convenient for the developed world that most of the global TB epidemic is elsewhere. However, in the words of Farmer and Kim (1998), "local epidemics don't stay local." In a global assessment MDRTB turned up in 34 out of 35 countries surveyed (Pablos-Mendez et al. 1998), and there are several documented cases of TB transmission on airliners. ${ }^{21}$ Bifani et al. (1996) and Farmer (1999b) cite multiple cases of MDRTB strains making their way across borders and between U.S. cities. Clearly, in the era of globalization and "free trade," closing the borders simply isn't a practical (or a humanitarian) solution. 
The advocacy of PIH has created new awareness that international health authorities cannot ignore drug resistance. But in a world in which TB causes one-quarter of all preventable deaths ${ }^{22}$ (with prospects for tens of millions more as MDRTB spreads and works its deadly synergy with AIDS), ${ }^{23}$ these efforts are only a start. The newly formed Global Alliance for TB Drug Development and the funds for TB research from the Gates Foundation are reasons for hope, but these efforts will need to be matched by government funding if a global treatment campaign is to become a reality. The good news is that such support would create new markets for existing second-line drugs, providing leverage for large buyers (such as the U.S. government) to negotiate lower drug prices.

Public health workers (and medical anthropologists) are familiar with the critique that magic-bullet approaches such as over-reliance on drugs represent a failure to see the social and epidemiological forest for the individual trees. However, given the variety of drug susceptibility profiles seen for MDRTB, it is clear that international public health models also have to change-and bring the trees (and quality of care!) back into the concept of the epidemiological forest.

If we're going to cure this most ancient of human plagues, the welfare of people (in all their aggregate and individual complexities) will have to be at the forefront of health planning, funding, and advocacy. To date, the outcomes from the PIH program of community-based treatment for MDRTB in Peru demonstrate that it is not only desirable, but also necessary and feasible to design international tuberculosis programs that are responsive to the unique situations of individual patients.

\section{ACKNOWLEDGMENTS}

This research was made possible by a Mellon-Sawyer Post-Doctoral Fellowship at the Center for the Study of Health, Culture and Society, Rollins School of Public Health, Emory University, during the spring semester, 1999; and by a Ford Foundation Peru Academic Exchange Fellowship, administered through the joint Duke University and University of North Carolina Program in Latin American Studies in June-July 1999. I'd like to express special thanks to the staffs of Partners in Health and Socios en Salud; and to the many other public health workers, scholars, and TB patients who shared their knowledge and experience with me during interviews in Atlanta, Boston, New York City, and Lima. 


\section{NOTES}

1. This article examines resurgent TB in Peru, but the research on which it is based was carried out as part of a comparative study of institutional responses to resurgent TB epidemics. That study compared a First World case- the New York City epidemic of the early 1990s - with a case in a developing country-Lima, Peru (see Smith-Nonini 2004). Between 1999 and 2000 I interviewed TB specialists in New York City and Boston, at the Centers for Disease Control and Prevention (CDC) in Atlanta and at the WHO in Geneva. Most of these were conducted in person, but some were conducted by telephone, with follow-up by e-mail. While in Lima I visited and observed TB programs at a government-run TB clinic, a hospital-based TB unit, and a non-governmental organization (NGO) that specialized in community-based TB care. Interview data were supplemented with a Lexus-Nexus search of media coverage of resurgent TB epidemics and with a review of the TB literature in medical, social science, and health policy journals. Rates of cure for MDRTB patients enrolled in treatment trials in Lima were updated in 2003-04 with information provided by Partners in Health.

2. Ministry of Health, "Situacion Actual de la Enfermedades Transmisibles en el Pais-1982," unpublished internal document.

3. Interview with Dr. Marcos Cueto, Lima, Peru, June 1999.

4. Interview with Dr. Pedro Suarez, Director, National Program of Tuberculosis Control, Ministry of Health, Lima, Peru, June 1999.

5. Interview with Dr. Rubin de Celis, Lima, Peru, June 1999.

6. Interview with Dr. Julio Castro, Lima, Peru, June 1999.

7. Ibid.

8. Interview with Beth Yeager, researcher for the Proyeto Salud y Nutrición Básica, Lima, Peru, June 1999.

9. The extent of the drug-resistant TB problem in Lima remains unclear because so many of the data are based on the patients who come to the clinics or hospitals. As of mid-1999 Dr. Robert Gilman, a U.S.-trained TB specialist at PRISMA (a Limabased NGO), reported that pediatric TB rates had not risen, which is a good sign. Also, unlike the situation in U.S. urban centers and Africa, relatively few TB patients in Peru are co-infected with HIV. On the other hand, in the Social Security Hospital where he worked, Gilman reported that about 50 percent of AIDS patients were getting active TB and that about 50 percent of those got MDRTB.

10. Interviews with PIH researchers and with Ministry of Health officials in 1999.

11. I conducted interviews with patients, health professionals and community health workers during a two-day visit to Socios en Salud, Carabayllo, Peru, June 1999, where I accompanied a health promoter on his daily rounds to patients' homes. I also visited an SES primary care clinic in a poor barrio.

12. MDRTB is defined as resistance to at least two drugs: rifampicin and isoniazid, the two antibiotics in first line TB treatment protocols.

13. Interview with Dr. Robert Canales of the Ministry's Technical Unit for TB, June 1999.

14. Interviews with SES administrators in Lima; and Farmer (1999b and 2000).

15. Interviews with Canales in Lima, June 1999; and Farmer (2000).

16. The cure rates were 68 percent for those who had previously undergone more than two TB drug regimens, 79 percent for those who had undergone exactly 
two previous treatment regimens, and 86 percent for those who had only undergone one or fewer previous treatment regimen. This is according to Sarah Van Norden, "MDR TB Treatment in Peru: An Update," PIH Bulletin, Winter 2003.

17. Phone interview with Dr. Marcos Espinal, Communicable Diseases Division, World Health Organization, Geneva, Switzerland, May 1999.

18. Interviews with Drs. Paul Farmer and Jim Yong Kim, 1999; and with Farmer, February 2000.

19. Interviews and background materials provided by Drs. Paul Farmer and Jim Yong Kim, Boston, February 1999, and from the Website of the Gates Foundation.

20. Walt (1994); De Cock (1999).

21. See MMWR (1995) for a CDC review of six such cases.

22. Alan Hinman, cited in Philip J. Hilts, "Victory over TB Seen as Thwarted by Budget Unit," New York Times, February 27, 1990: 24.

23. An HIV+ person who is exposed to (drug-susceptible or drug-resistant) TB has a far higher chance of becoming infected, and of coming down with active disease, than does an HIV- person. Once an HIV+ person tests positive for $\mathrm{TB}$ on a skin test, that individual runs a 10 percent chance of coming down with active TB within a year, according to Dr. Jim Curran, Dean of the Rollins School of Public Health, Emory University, and former director of AIDS research at the CDC, (interview, February 2000).

\section{REFERENCES}

Bayer, Ronald, Stayton, C. Desvarieux, Moise, Cheryl Healton, Sheldon Landesman, and Wei-Yann Tsai

1998 Directly Observed Therapy and Treatment Completion in the United States: Is Universal Supervised Therapy Necessary? American Journal of Public Health 88(7):1052-1058.

Becerra, M. C., J. Bayona, J. Freeman, P. E. Farmer, and J. Y. Kim

2000 Redefining MDR-TB Transmission "Hot Spots." International Journal of Tuberculosis and Lung Disease 4(5):387-394.

Bifani, P. J., B. B. Plikaytis, and V. Kapur

1996 Origin and Interstate Spread of a New York City Multidrug Resistant Mycobacterium. Tuberculosis Clone Family. Journal of the American Medical Association 75:452-457.

Bill and Melinda Gates Foundation Global Health Initiative, www.gatesfoundation. org/GlobalHealth/

Briggs, Charles L. and Clara Mantini-Briggs

2003 Stories in the Time of Cholera: Racial Profiling During a Medical Nightmare. Berkeley: University of California Press.

Chaulk, C. Patrick, Kristina Moore-Rice, Rosetta Rizzo, and Richard E. Chaisson

1995 Eleven Years of Community-Based Directly Observed Therapy for Tuberculosis. Journal of the American Medical Association 274(12):945-951.

Chossudovsky and Michel

1997 IMF Shock Treatment in Peru. In The Globablisation of Poverty: Impacts of IMF and World Bank Reforms. London: Zed Books. 
Cohn, David, F. Bustreo, and Mario Raviglione

1997 Drug Resistant Tuberculosis: Review of the Worldwide Situation and the WHO/IUATLD Global Surveillance Project. Clinical Infectious Diseases 24(Suppl. 1):S121-130.

Cortez, Rafael and Cesar Calvo

1996-97 La Nutricion Infantil en el Peru. Punto de Equilibrio 46(6). Dic/Enero.

Cueto, Marcos

1997 El Regreso de las Epidemias: Salud y Sociedad en el Peru del Siglo XX. Lima: Instituto de Estudios Peruanos.

De Cock, Kevin

1999 International Responses to HIV/AIDS. Paper presented in Sawyer Seminar on Emerging Illnesses and Institutional Responses, Rollins School of Public Health, Emory University, April 2.

Fairchild, A. L. and G. M. Oppenheimer

1998 Public Health Nihilism vs. Pragmatism: History, Politics and the Control of Tuberculosis. American Journal of Public Health 88:1105-1117.

Farmer, Paul

1992 AIDS and Accusation: Haiti and the Geography of Blame. Berkeley: University of California Press.

1997 Social Scientists and the New Tuberculosis. Social Science and Medicine 44(3):347-358.

1999a Infections and Inequalities: The Modern Plagues. Berkeley: University of California Press.

1999b Hidden Epidemics of Tuberculosis. Working Paper No. 239, Latin American Program, Woodrow Wilson International Center for Scholars.

Farmer, Paul and Jim Yong Kim

1998 Community-Based Approaches to the Control of Multi-Drug Resistant Tuberculosis: Introducing DOTS-Plus. British Medical Journal 317:671-674.

Farmer, Paul and Ed Nardell

1998 Editorial: Nihilism and Pragmatism in Tuberculosis Control. American Journal of Public Health 88(7):1014-1015.

Frieden, Thomas, Paula Fujiwara, Rita Washko, and Margaret Hamburg

1995 Tuberculosis in New York City: Turning the Tide. The New England Journal of Medicine 333(4):229-233.

Gandy, Matthew and Alimuddin Zumla

2003 The Return of the White Plague: Global Poverty and the New Tuberculosis. London: Verso.

Garrett and Laurie

1994 The Coming Plague: Newly Emerging Diseases in a World out of Balance. New York: Penguin Books.

Harantani, Joseph and Donald Hernandez

1991 Cholera in Peru: A Rapid Assessment of the Country's Water and Sanitation Infrastructure. Washington, DC: USAID Mission to Peru. 
Heymann, Jody, Randall Sell, and Timothy Brewer

1998 The Influence of Program Acceptability on the Effectiveness of Public Health Policy: A Study of Directly Observed Therapy for Tuberculosis. American Journal of Public Health 88(3):442-445.

Hopewell, Philip, Bernardus Ganter, Robert Baron, and Mauro Sanchez-Hernandez

1985 Operational Evaluation of Treatment for Tuberculosis: Results of 8- and 12-Month Regimens in Peru. American Review of Respiratory Disease 132(4):737-41.

Hopewell, Philip, Mauro Sanchez-Hernandez, Robert Baron, and Bernardus Ganter

1984 Operational Evaluation of Treatment for Tuberculosis: Results of a "Standard" 12-Month Regimen in Peru. American Review of Respiratory Disease 129:439-443.

Kidder, Tracy

2004 Mountains Beyond Mountains: The Quest of Dr. Paul Farmer, A Man Who Would Cure the World. New York: Random House.

Kim, Jim Yong, Joyce V. Millen, Alec Irwin, and John Gershman

2000 Dying for Growth: Global Inequality and the Health of the Poor. Monroe, M.E.: Common Courage Press.

Kim, Jim Yong, Aaron Shakow, and Jaime Bayona, Joe Rhatigan and Emma L. Rubin de Celis

2000 Sickness Amidst Recovery: Public Debt and Private Suffering in Peru. In Dying for Growth: Global Inequality and the Health of the Poor. Jim Yong Kim, Joyce V. Millen, Alec Irwin, and John Gershman, eds. Pp. 127-153. Monroe, M.E.: Common Courage Press.

Laszlo, A. and I. N. Kantor

1994 A Random Sample Survey of Initial Drug Resistance among Tuberculosis Cases in Latin America. Bulletin of the World Health Organization 72(4):603-610.

Lederberg, Joshua

1996 Infectious Disease: A Threat to Global Health and Security. Editorial. Journal of the American Medical Association 276(5):417-419.

Lerner, Barron $\mathrm{H}$.

1993 New York City's Tuberculosis Control Efforts: The Historical Limitations of the "War on Consumption." American Journal of Public Health 83(5): 758-766.

McClintock, Cynthia

1989 Peru's Sendero Luminoso Rebellion: Origins and Trajectory. In Power and Popular Protest: Latin American Social Movements. Susan Eckstein, ed. Pp. 61-101. Berkeley: University of California Press.

1983 Ministerio de Salud del Peru HealthCuadro No. 5: Mortalidad y Morbilidad por tuberculosis. Informe Estadistico Anual de Enfermedades Transmisibles, 1963-1983, OGIE.

1997 Tuberculosis en el Peru, Informe 1997

Pablos-Mendez, Ariel, Mario Raviglione, Adalbert Laszlo, Nancy Binkin, Hans L.

Rieder, Flavia Bustreo, David L. Cohn, Caterina S. B. Lambregts-van Weezenbeek,

Sang Jae Kim, Pierre Chaulet, and Paul Nunn

1998 Global Surveillance for Antituberculosis-Drug Resistance, 1994-1997. New Eng. Journal of Medicine 338(23):1641-1649. 
PSNB

1998 Estudio Sociomedico sobre la Tuberculosis: Lima. Informes de Investigacion 12, Proyecto Salud y Nutricion Basica, Lima, Peru.

Reichman, Lee

1997 Defending the Public's Health against Tuberculosis. JAMA 278(10):865-867.

Sanghavi, Darshak M., Robert H. Gilman, Andres G. Lescano-Guevara, William

Checkley, Lilia Z. Cabrera, and Vicky Cardenas

1998 Hyperendemic pulmonary tuberculosis in a Peruvian shantytown. American Journal of Epidemiology 148(4):384-389.

Smith-Nonini, Sandy

2004 The Cultural Politics of Institutional Responses to Resurgent Tuberculosis Epidemics: New York City and Lima, Peru. In Emerging Illnesses and Society: Defining the Public Health. Ruth Berkelman, Peter Brown, Howard Frumkin, and Randall M. Packard, eds. Pp. 253-290. Baltimore and London: Johns Hopkins University Press.

Wallace, Rodrick and Deborah Wallace

1998 A Plague on Your Houses: How New York was Burned Down and Public Health Crumbled. New York: Verso.

Walt, Gill

1994 Health Policy: An Introduction to Process and Power. London: Zed Books.

Weis, Stephen, Philip C. Slocum, Francis X. Blais, Barbara King, Mary Nunn, G. Burgis Matney, Enriqueta Gomez, and Brian H. Foresman

1994 The Effect of Directly-Observed Therapy on the Rates of Drug Resistance and Relapse in Tuberculosis. New England Journal of Medicine 330(17):1179-1184. 